\title{
The effect of various pressure of pneumatic uterine bracket by using saccule sterine external stent on incidence of supine hypotensive syndrome
}

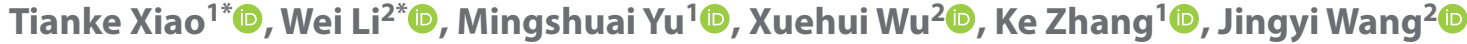 \\ ${ }^{1}$ Department of Anesthesiology, CNNC $416^{\text {th }}$ Hospital, The Second Affiliated Hospital of Chengdu Medical College, China \\ ${ }^{2}$ Department of Obstetrics and Gynecology, CNNC $416^{\text {th }}$ Hospital, The Second Affiliated Hospital of Chengdu Medical College, China
}

*These Authors contributed equally to this manuscript

\begin{abstract}
Objectives: The saccule uterine external stent with a pneumatic uterine bracket reportedly prevents the incidence of supine hypotension syndrome (SHS) during cesarean section under combined spinal — epidural anesthesia (CSEA). However, the preventive effect is affected by the pressure within pneumatic uterine bracket. This study aims to explore the optimal pressure. Material and methods: One hundred forty-eight pregnant women were selected and randomly divided into three groups: Group A (the control group, $n=49)$, Group B $(n=49)$, and Group C $(n=50)$. The pressure within pneumatic uterine bracket was set at $240 \mathrm{mmHg}, 260 \mathrm{mmHg}$, and $280 \mathrm{mmHg}$, respectively, during cesarean section under CSEA for participants in groups A, B and C. The intraoperative comfort rate and incidence of SHS were recorded.

Results: No significant difference in the anesthetic efficacy was observed among the three groups $(p>0.05)$. However, there was a significant difference in the occurrence of SHS, with a reduction of $30 \mathrm{mmHg}$ in blood pressure. The incidence of SHS belong the three groups showed significant differences (36.73\% in Group A, 18.37\% in Group B and 18.00\% in Group C, $p<0.05)$. In addition, significant differences $(p<0.05)$ in the intraoperative comfort rate were also found among the three groups, with the comfort rate of $69.39 \%$ in group A, $91.84 \%$ in group B and $90.00 \%$ in Group C.

Conclusions: The optimal pressure within pneumatic uterine bracket for preventing SHS hypotension is about $260 \mathrm{mmHg}$ These findings might contribute to the prevention of SHS.

Key words: pneumatic uterine bracket; gasbag pressure; cesarean section; supine hypotension syndrome
\end{abstract}

Ginekologia Polska 2021; 92, 7: 505-511

\section{INTRODUCTION}

Supine hypotensive syndrome (SHS) is characterized by severe supine hypotension in late pregnancy. The clinical presentations of SHS include dyspnea, dizziness, nausea and vomiting. The intrinsic hypotension in parturients further decreases the fetoplacental blood flow, thus resulting in fetal intrauterine hypoxia, acidosis and even post-neonatal cerebral palsy [1]. These symptoms were reportedly relieved by turning to the lateral position [2]. In addition, the occurrence of SHS is associated with anesthesia methods and anesthetic drugs, which account for the significant differences in incidence of SHS reported by different studies [3,4]. Combined spinal-epidural anesthesia (CSEA) is a common anesthesia method that widely used in obstetrics. Because CSEA avoids the adverse effects of anesthetic drugs on the fetus under the general anesthesia and facilitates postoperative analgesia efficiently [3]. However, CSEA has been reported to increase the incidence of SHS after the anesthesia [4]. The incidence of SHS in pregnant women was significantly increased after the anesthesia, with the incidence of $80 \%$ [5].

A self-made pneumatic uterine bracket has been found to perform excellent clinical efficacy in reducing the incidence of SHS during the cesarean section (Chinese National Patent for Utility Modes.: ZL 201320122209.6). However, the air sac pressure of the equipment enhances requirement for materials of final product. The joint stress points and

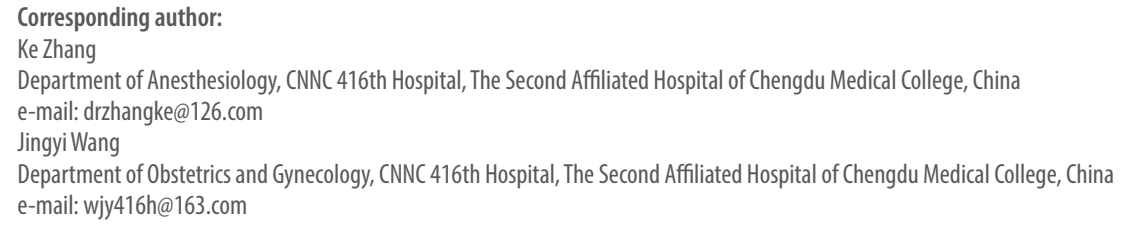


air-adding pathways on both sides of pneumatic uterine bracket are integrated plate structure. After installation, the plate structure is located between the waist of parturients and surgical beds. The gasbags on both sides of pneumatic uterine bracket are fixed at the soft part between costal margins (the left and right costal margins) and the ilium via the middle plate structure. Therefore, the improved pressure within the gasbags demands increased load-bearing ability and increased thickness of the plate structure. While the increased thickness of the plate structure is associated with severe lumbar hyperextension of parturients after installation.

\section{Objectives}

This study aims to investigate the influence of different air sac pressure on the incidence of SHS and comfort level of the puerperas and determine the optimal pressure.

\section{MATERIAL AND METHODS}

\section{Subjects}

One hundred forty-eight puerperas, aged from 28 to 42 years old, of American Society of Anesthesiologists (ASA) grading I to II were recruited for cesarean section under CSEA between May 2018 and April 2019 in The Second Affiliated Hospital of Chengdu Medical College. Exclusion: (1) Puerperas with gestational hypertension (the diagnostic criteria was according to the 2018 International Society for the Study of Hypertension in Pregnancy Classification, Diagnosis and Management Guidelines); (2) The anesthesia block plane was T4-T6; (3) The epidural injection of local anesthetic drugs before the operation due to poor anesthetic effect; (4) The neonatal weight is less than $2 \mathrm{Kg}$. All participants signed the informed consent document, and the research was approved by the Ethics Committee of The Second Affiliated Hospital of Chengdu Medical College.

Participants were randomly divided into three groups: Group A (control group, $n=49)$, Group B $(n=49)$, and Group $C(n=50)$. Pressure of pneumatic uterine bracket was set at $240 \mathrm{mmHg}, 260 \mathrm{mmHg}$, and $280 \mathrm{mmHg}$, respectively, during cesarean section under CSEA for participants in groups $A$, $B$ and $C$. The age, height, weight, gestational age, uterine height, abdominal perimeter and newborn weight were collected. Whether puerperas had SHS before anesthesia was also identified.

\section{Anesthesia methods}

CSEA was used for all parturients. After the parturient entering the operation room, oxygen was inhaled at $4 \mathrm{~L} / \mathrm{min}$ via the face mask. Electrocardiogram (ECG), blood pressure (BP), heart rate (HR) and oxygen saturation of the parturient were monitored. Meanwhile, $500 \mathrm{~mL}$ of colloid solution was rapidly infused. Fifteen milligrams of ropivacaine hydrochloride were injected into subarachnoid cavity rapidly. The epidural
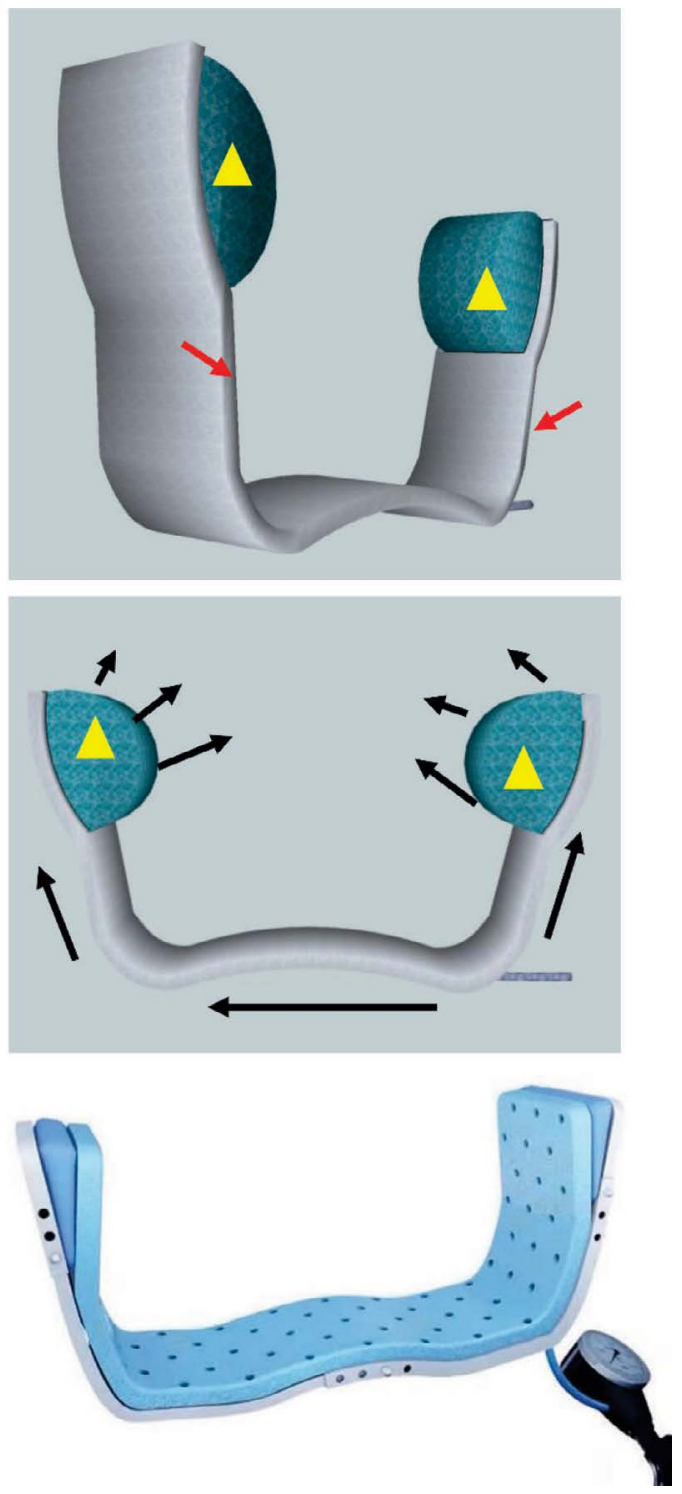

Figure 1. The structure of pneumatic uterine bracket. Yellow triangles indicate the gasbags. Red arrows indicate the air-adding pathways. Black arrows indicate the direction of air flow and pressure

catheterization was standby. After fixing the epidural pipe, pneumatic uterine bracket (the structure of the pneumatic uterine bracket was shown in Fig. 1) was installed immediately. The installation position was at back waist, and gasbags on both sides of pneumatic uterine bracket were fixed at the soft part between costal margins (left and right costal margins) and ilium via the middle plate structure (installation method was illustrated in Fig. 2). Subsequently, parturients were turned to a prostrate position. Gasbags in groups $A$, $B$, and $C$ was pressurized to $240 \mathrm{mmHg}, 260 \mathrm{mmHg}$, and $280 \mathrm{mmHg}$, respectively. Pressurization time of the air bags was five to seven minutes. Air pressure within gasbags was decompressed rapidly after the incision of lower segment of the uterus and suction of the amniotic fluid. The lateral decu- 

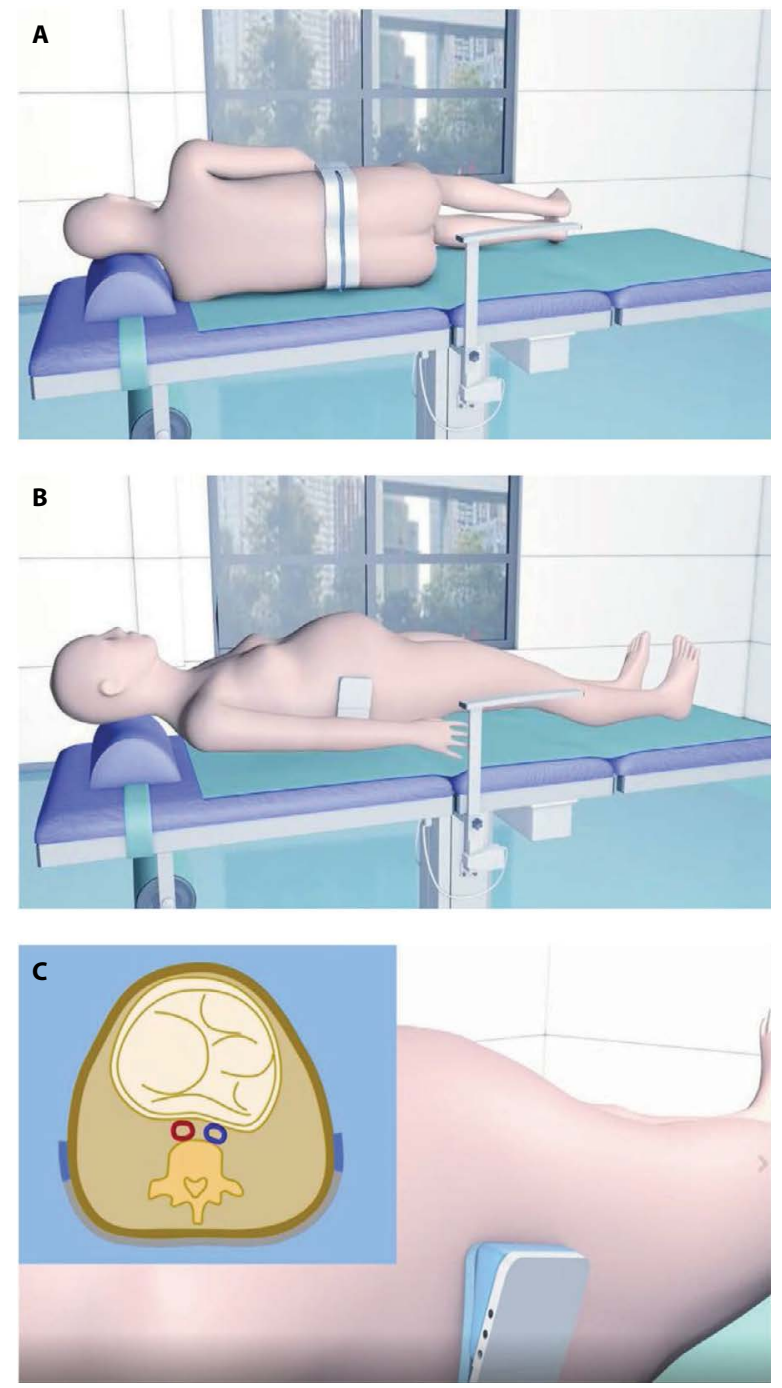

Figure 2. The installation method of pneumatic uterine bracket; A. After the installation, the plate structure was installed at the back of the maternal waist to make sure that the gasbags were fixed at the soft part between costal margins and the ilium; B. Parturient lying on the operating table after the installation; $\mathbf{C}$. Pressurized gasbags separated the enlarged uterus from the compressed inferior vena cava

bitus time of parturients in all groups was within two minutes after subarachnoid injection. Data were then recorded.

\section{Observation indicators}

Evaluation of the anesthetic effect

The degree of pain was judged by a visual analogue scale (VAS). Pain scores ranged from 0 to 10 points, where 0 represents No pain and 10 represents Maximum pain imaginable. Scores were recorded at skin incision, fetal removal and closure suture.

The degree of muscle relaxation was evaluated by the surgeon. An evaluation was conducted at the end of the operation according to the commonly used evaluation criteria. The degree of muscle relaxation included three subscales: "very satisfied", "satisfied", and "dissatisfied".
The "very satisfied" subscale reflects high plane of anesthesia, good muscle relaxation and good anesthetic effect, which do not affect the surgical procedures. The "satisfied" subscale corresponds to acceptable interference by relative muscle relaxation. While the "dissatisfied" subscale reflects low plane of anesthesia and poor muscle relaxation, which severely affects surgical procedures.

\section{Main indicators of SHS}

Because SHS are mainly occurred three to seven minutes after subarachnoid injection of local anesthetics (i.e., the period ranging from anesthesia complete to lower uterine segment incision) [6]. Maternal hemodynamics during this period were evaluated. The number of subjects whose heart rate $(\mathrm{HR})$ was increased by 20 beats/min, the number of subjects whose systolic blood pressure was decreased by $4 \mathrm{kPa}(30 \mathrm{mmHg})$, the number of subjects whose systolic blood pressure dropped below $10.6 \mathrm{kPa}(80 \mathrm{mmHg})$, and the number of subjects with severe SHS were recorded. Participants with HR above 120 beats/min and systolic blood pressure below $70 \mathrm{mmHg}$ should be treated in time to avoid compression of the inferior vena cava through the change of body position and injection of ephedrine (10 mg).

\section{Evaluation of maternal adverse reactions}

The number of parturients feeling dizziness, dyspnea, nausea and vomiting during the operation was recorded. The adverse reactions were assessed by the comfort level of the puerperas during the operation and included three subscales: "very satisfied (no discomfort)", "satisfied (slight and tolerable discomfort)" and "dissatisfied (serious discomfort)".

\section{Statistical methods}

The measurement data were presented as mean \pm standard deviation $(\bar{\chi} \pm s)$. The differences in groups were tested by analysis of variance. An LSD test was used for the post-hoc test. Enumeration data were tested by chi-square test. All d statistical analyses were performed using the SPSS23.0 software. $P<0.05$ was considered as statistically significant.

\section{RESULTS}

\section{Basic data of all puerperas}

The basic information of puerperas was presented in Table 1. As shown in Table 1, there was no significant difference in the age, height, weight, pregnant period, uterine height, abdominal perimeter, neonatal weight and the percentage of parturients with SHS before anesthesia among the three groups $(p>0.05)$.

\section{Anesthetic effect under different pressure}

The degree of pain and muscle relaxation was presented in Table 2. As shown in Table 2, there was no significant dif- 


\begin{tabular}{|c|c|c|c|c|c|c|c|c|c|}
\hline & \multirow[t]{2}{*}{ Age } & \multirow[t]{2}{*}{ Hight $[\mathrm{cm}]$} & \multirow[t]{2}{*}{$\begin{array}{l}\text { Weight } \\
\text { [kg] }\end{array}$} & \multirow[t]{2}{*}{$\begin{array}{l}\text { Pregnant } \\
\text { period [d] }\end{array}$} & \multirow{2}{*}{$\begin{array}{l}\text { Uterine } \\
\text { height } \\
\text { [cm] }\end{array}$} & \multirow{2}{*}{$\begin{array}{l}\text { Abdominal } \\
\text { perimeter } \\
{[\mathrm{cm}]}\end{array}$} & \multirow[t]{2}{*}{$\begin{array}{l}\text { Neonatal } \\
\text { weight [g] }\end{array}$} & \multicolumn{2}{|c|}{$\begin{array}{l}\text { Whether parturients } \\
\text { had SHS before } \\
\text { anesthesia }\end{array}$} \\
\hline & & & & & & & & Yes & No \\
\hline Group A & $30.69 \pm 2.66$ & $159.04 \pm 4.82$ & $69.00 \pm 9.43$ & $272.20 \pm 7.39$ & $33.82 \pm 2.12$ & $102.71 \pm 6.97$ & $3350.00 \pm 348.14$ & $13(26.53 \%)$ & $36(73.47 \%)$ \\
\hline Group B & $31.59 \pm 2.78$ & $158.14 \pm 4.91$ & $68.37 \pm 8.73$ & $272.43 \pm 7.05$ & $33.33 \pm 2.15$ & $102.20 \pm 6.40$ & $3243.06 \pm 321.93$ & $11(22.45 \%)$ & 38 (77.55\%) \\
\hline Group C & $30.68 \pm 3.52$ & $158.18 \pm 3.73$ & $67.73 \pm 9.03$ & $272.20 \pm 8.13$ & $34.00 \pm 2.52$ & $101.68 \pm 6.00$ & $3331.20 \pm 458.19$ & $14(28.00 \%)$ & $36(72.00 \%)$ \\
\hline$F / \chi^{2}$ & 1.613 & 0.622 & 0.245 & 0.015 & 1.156 & 0.317 & 1.101 & 0.428 & \\
\hline$p$ & 0.203 & 0.538 & 0.783 & 0.985 & 0.318 & 0.719 & 0.335 & 0.842 & \\
\hline
\end{tabular}

Note: There was no significant difference among the three groups and no further pairwise comparison was required

\begin{tabular}{|c|c|c|c|c|c|}
\hline \multirow[b]{2}{*}{ Groups } & \multicolumn{3}{|l|}{ VAS scores } & \multicolumn{2}{|c|}{ Evaluation of abdominal muscle relaxation } \\
\hline & $\begin{array}{l}\text { During incision } \\
\text { (M1) }\end{array}$ & Fetus extraction (M2) & $\begin{array}{l}\text { During stitching } \\
\text { (M3) }\end{array}$ & Very satisfied & Dissatisfied \\
\hline Group A ( $n=49)$ & $1.49 \pm 0.68$ & $2.31 \pm 1.21$ & $1.49 \pm 0.65$ & $44(89.80 \%)$ & $5(10.20 \%)$ \\
\hline Group B $(n=49)$ & $1.51 \pm 0.62$ & $2.47 \pm 1.23$ & $1.47 \pm 0.62$ & $42(85.71 \%)$ & $7(14.29 \%)$ \\
\hline Group C $(n=50)$ & $1.58 \pm 0.73$ & $2.68 \pm 1.48$ & $1.56 \pm 0.67$ & $43(86.00 \%)$ & $7(14.00 \%)$ \\
\hline$F / \chi^{2}$ & 0.242 & 1.011 & 0.268 & \multicolumn{2}{|c|}{0.796} \\
\hline$p$ & 0.786 & 0.366 & 0.766 & \multicolumn{2}{|c|}{0.863} \\
\hline
\end{tabular}

VAS - visual analogue scale

ference in VAS scores among three groups at skin incision (M1), fetal removal (M2) and closure suture (M3) ( $p>0.05)$. The evaluation of abdominal muscle relaxation by surgeons demonstrated that 5 patients in group $A(10.20 \%), 7$ patients in group $B(14.29 \%)$ and 7 patients in group $C(14.00 \%)$ were dissatisfied. There was no significant difference in anesthetic effect among the three groups ( $p>0.05$ ).

\section{The incidence of SHS under different pressure}

During the period from subarachnoid injection to the incision of the lower uterine segment, the incidence of the SHS among the three groups were shown in Table 3. As shown in Table 3, in Group A, there were 26 (53.06\%) cases showing increased heart rate of more than 20 beats/min, 18 cases $(36.73 \%)$ showing a decrease in systolic blood pressure of $4 \mathrm{kPa}(30 \mathrm{mmHg})$, and 12 cases $(24.49 \%)$ showing a decrease in systolic blood pressure to $10.6 \mathrm{kPa}(80 \mathrm{mmHg})$. There were 13 cases (26.3\%) showing severe SHS that must be timely treated in group A. In Group B, there were 17 cases (34.69\%) showing increased heart rate of more than 20 beats/min, 9 cases (18.37\%) showing a decrease in systolic blood pressure of $4 \mathrm{kPa}$ (30 $\mathrm{mmHg}$ ), and cases (8.16\%) showing a decrease in systolic blood pressure to $10.6 \mathrm{kPa}(80 \mathrm{mmHg})$. There were 5 cases (10.20\%) showing severe SHS that must be timely treated in group B. In Group C, there were 15 cases (30\%) showing increased heart rate of more than 20 beats/min, $9(18.00 \%)$ cases showing a decrease in systolic blood pressure of $4 \mathrm{kPa}(30 \mathrm{mmHg})$, and 4 cases (8.00\%) showing a decrease in systolic blood pressure to $10.6 \mathrm{kPa}(80 \mathrm{mmHg})$. There were 5 cases $(10.00 \%)$ showing severe SHS that must be timely treated in group $C$. The results from chi-square tests reflecting SHS incidence were shown in Table 3. As shown in Table 3, the difference in $\mathrm{SHS}$ incidence between groups $\mathrm{A}$ and $\mathrm{B}$ was significant $(p<0.05)$. SHS incidence also showed significant difference between groups $A$ and $C(p<0.05)$. However, no significant difference in the incidence of $\mathrm{SHS}$ between groups $B$ and $C(p>0.05)$ was observed. It was also found that the incidence of SHS in Group A was significantly higher than that in other two groups (Tab. 3).

\section{Comfort level and intraoperative adverse reactions in parturients}

As shown in Table 4, intraoperative dizziness occurred in 14 cases (28.57\%), 5 cases (10.20\%) and 4 cases (8.00\%) in groups $A, B$ and $C$, respectively. Obviously, the incidence of intraoperative dizziness in parturients from group $A$ was significantly higher than that in parturients from groups $B$ and $C(p<0.05)$, while there was no significant difference in the incidence of intraoperative dizziness in parturients from groups $B$ and $C(p>0.05)$. During the operation, the incidences of nausea and vomiting in group $A$, group $B$, and group $C$ were $26.53 \%, 8.16 \%$ and $10.00 \%$, respectively. The incidence of nausea and vomiting in group $A$ was significantly higher than that in groups $B$ and $C(p<0.05)$, with 
Table 3. The incidence of supine hypotension syndrome pregnant women

\begin{tabular}{|c|c|c|c|c|}
\hline \multirow[b]{2}{*}{ Groups } & \multicolumn{4}{|c|}{ Period from subarachnoid injection to the incision } \\
\hline & $\begin{array}{l}\text { Heart rate increased } \\
\text { by more than } \\
20 \text { beats } / \mathrm{min}\end{array}$ & $\begin{array}{l}\text { Systolic blood pressure } \\
\text { decreased by } 4 \mathrm{kPa} \\
(30 \mathrm{mmHg} \text { ) }\end{array}$ & $\begin{array}{l}\text { Systolic blood pressure } \\
\text { decreased to } 10.6 \mathrm{kPa} \\
(80 \mathrm{mmHg})\end{array}$ & $\begin{array}{l}\text { Cases with severe SHS that } \\
\text { must be timely treated }\end{array}$ \\
\hline Group A $(n=49)$ & $26(53.06 \%)$ & $18(36.73 \%)$ & $12(24.49 \%)$ & $13(26.53 \%)$ \\
\hline Group B $(n=49)$ & $17(34.69 \%)^{\mathrm{a}}$ & $9(18.37 \%)^{\mathrm{a}}$ & $4(8.16 \%)^{\mathrm{a}}$ & $5(10.20 \%)$ \\
\hline Group C $(n=50)$ & $15(30.00 \%)^{\mathrm{a}}$ & $9(18.00 \%)^{\mathrm{a}}$ & $4(8.00 \%)^{\mathrm{a}}$ & $5(10.00 \%)$ \\
\hline$\chi^{2}$ & 6.144 & 6.131 & 7.552 & 3.950 \\
\hline $\mathrm{p}$ & $0.046^{*}$ & $0.047^{*}$ & $0.023^{*}$ & 0.139 \\
\hline
\end{tabular}

${ }^{*} \mathrm{p}<0.05$; aCompared with group A, there were significant differences; SHS — supine hypotension syndrome

Table 4. The degree of adverse reactions of the puerperas

\begin{tabular}{|l|l|l|l|l|}
\hline \multirow{2}{*}{ Groups } & After anesthesia & & \\
\cline { 2 - 5 } & Dizziness & Nausea and vomiting & Dyspnea & $\begin{array}{l}\text { Comfort evaluation (very } \\
\text { satisfied and satisfied) }\end{array}$ \\
\hline Group A $(n=49)$ & $14(28.57 \%)$ & $13(26.53 \%)$ & $9(18.37 \%)$ & $34(69.39 \%)$ \\
\hline Group B $(n=49)$ & $5(10.20 \%)^{\mathrm{a}}$ & $4(8.16 \%)^{\mathrm{a}}$ & $4(8.16 \%)$ & $45(91.84 \%)^{\mathrm{a}}$ \\
\hline Group C $(\mathrm{n}=50)$ & $4(8.00 \%)^{\mathrm{a}}$ & $5(10.00 \%)^{\mathrm{a}}$ & $4(8.00 \%)$ & $45(90.00 \%)^{\mathrm{a}}$ \\
\hline$\chi^{2}$ & 9.568 & 7.943 & 3.326 & 11.235 \\
\hline$p$ & $0.014^{*}$ & $0.019^{*}$ & 0.230 & $0.004^{*}$ \\
\hline
\end{tabular}

${ }^{*} \mathrm{p}<0.05$; ${ }^{\mathrm{C}} \mathrm{Compared}$ with group $\mathrm{A}$, there were significant differences

no significant difference observed between group $B$ and $C$ $(p>0.05)$. In addition, the incidence of dyspnea in group $A$, group $B$, and group C were $18.37 \%, 8.16 \%$ and $8.00 \%$, respectively. The incidence of dyspnea was significantly higher in group A than that in groups B (8.16\%) and C (8.00\%), with no significant difference found in the incidence between groups B and group C $(p<0.05)$.

After the operation, 34 cases (69.39\%) in group $A, 45$ cases $(91.84 \%)$ in group $B$ and 45 cases $(90.00 \%)$ in group $C$ were highly satisfied and satisfied. The comfort rate in group $A$ was significantly lower than that in group $B$ and $C(p<0.05)$, and there was no significant difference in the comfort rate between group $B$ and $C(p>0.05)$. Compared with group $A$, there were significant adverse reactions caused by blood pressure reduction during the operation between group $B$ and group $C(p<0.05)$, while there were no significant differences in the adverse reactions caused by blood pressure reduction during the operation between groups $B$ and group $C(p>0.05)$. There were significant differences among the three groups in the comfort level during the obstetrics $(p<0.05)$, with parturient in the group $B$ having highest comfort rate.

\section{DISCUSSION}

The occurrence of SHS in parturients under CSEA is related to many factors, including maternal age, fetal weight and the presence or absence of SHS in late pregnancy $[7,8]$.
The newborns in China in 2018 and 2019 was 15.23 million and 14.65 million, respectively. In 2018, the cesarean section rate was $36.7 \%$, which indicates that more than five million puerperas receive cesarean sections every year. How to reduce the incidence of SHS, improve the maternal satisfaction and ensure the safety of newborns has been a critical topic for both anesthesiologists and obstetricians.

The commonly used methods for the prevention and treatment of SHS include expansion before spinal anesthesia $[9,10]$, administration of pressure-boosting drugs [11-14], administration of the isobaric local anesthetic drugs and reduction of the dosage of local anesthetic drugs, and pre-evaluation of SHS before operation [10, 15]. However, these methods suffer from drawbacks.

The pathophysiology of SHS indicates the postural intervention as the best way to prevent the incidence of SHS. Clinically, the commonly used methods are to tilt the surgical bed to the left, move the uterus to the left, and place wedges under the lumbar spine of the puerpera [16]. Because the uterus mostly is in the right position, the enlarged uterus after left inclination avoids the serious compression on inferior vena cava and abdominal aorta and increases the volume of blood regurgitation, thus decreasing the occurrence of hypotension fundamentally and reducing the degree of hypotension even if SHS occurs. However, in clinical practice, postural intervention is usually unable to be implemented 
due to the influence of surgery and the non-ideal environment. Kundra et al. [17], reported that the left shift of the uterus as far as possible by manipulation in the supine position of parturients after spinal anesthesia can effectively avoid the oppression of the uterus on the abdominal aorta and the inferior vena cava. However, the manipulation, which seriously affects the disinfection and surgical operations, is difficult to conduct. The excessive left-leaning surgical beds also greatly increase the fear of the puerperas, thus further influencing the maternal satisfaction.

The pneumatic uterine bracket used in the present study is another form of postural intervention, and its structure diagram is shown in Figure 1. Our previous study [18] confirmed that this method is superior to traditional methods, which ensures the advantages of postural intervention (i.e., to effectively prevent the occurrence of SHS), without affecting the operations of surgeons and anesthesiologists or increasing maternal discomfort.

However, we found problems in the selection of the proper materials for the subsequent mass production. In the previous research, a metal skeleton has been selected to produce pneumatic uterine brackets. The metal plate used in the previous study was very hard and had a small deformation arc after compression, so even the metal plate with the thickness of $0.5 \mathrm{~cm}$ can meet the balloon pressure above $280 \mathrm{mmHg}$ [18]. The installation method of the pneumatic uterine bracket was shown in Figure 2. The reaction force support points of the pressure depend completely on double side gasbags between the board structure. After the installation, the plate structure with hidden inflation tubes is located between the physiological curvature of the back waist of the parturients and the operation bed. In our previous research, the metal structure, which was extremely hard and had small deformation curves after compression was utilized. Therefore, the sheet metal even with a thickness of $0.5 \mathrm{~cm}$ can support the pressure above $280 \mathrm{mmHg}$ within the gasbags [18]. The mass production and large area promotion of pneumatic uterine bracket demand the usage of medical polyvinyl chloride (PVC). Medical PVC materials are also required in order to ensure the low cost and easy operation. High pressure requires the increased thickness of the PVC link plate in the middle. The enhanced thickness will cause the obvious the overextension of the back waist of the parturients, thus reducing the maternal comfort. The purpose of this study was to investigate the minimum pressure that can effectively prevent the incidence of SHS after balloon pressurization and to reduce the thickness of disposable medical PVC products of pneumatic uterine brackets.

In this study, during the period from anesthesia to the incision of the lower uterine segment, the proportions of parturients with systolic blood pressure decreased by $4 \mathrm{kPa}$
( $30 \mathrm{mmHg}$ ) and systolic blood pressure decreased to below $10.6 \mathrm{kPa}(80 \mathrm{mmHg})$ and parturients receiving prompt treatment were significantly higher in Group $A$ than that in groups $B$ and $C$, with no significant difference observed between groups $B$ and $C$. The results indicated that the pressure of $240 \mathrm{mmHg}$ did not contribute to prevent the incidence of SHS. For the proportion of parturients with heart rate increased more than $>20$ beats/min was the highest in Group A, there was no significant difference between groups $A$ and $B$. Therefore, a larger sample size is needed to confirm the difference between groups $A$ and $B$ in further studies. The comparison results of maternal adverse reactions (including dizziness, nausea, vomiting and comfort) among the three groups demonstrated that, such as and comfort evaluation, both of Group B and Group C were better than Group A. The maternal comfort level of Group A was significantly lower, which was also related to the imperfect role of Group A in preventing SHS hypotension. There was no significant difference in the rate of dyspnea within the three groups, indicating that the compressed bilateral gasbags raised the uterus efficiently to avoid dyspnea derived from the compression. In the study, we also observed that two cases in Group C were dissatisfied with the comfort level because of the tight feelings around the waist. Although there was no significant statistical difference between Group C and Group B, further observation was still needed with the increasing of the sample size.

It can be judged from this study that the pressure of $260 \mathrm{mmHg}$ can effectively maintain the effect of pneumatic uterine bracket to prevent SHS hypotension, and meanwhile avoid the discomfort caused by the high blood pressure of the puerpera. It is the minimum blood pressure requirement of pneumatic uterine bracket to prevent SHS hypotension.

\section{CONCLUSIONS}

The minimum pressure of Pneumatic uterine bracket for preventing SHS hypotension is about $260 \mathrm{mmHg}$. Under such a pressure, the desired prevention effect of SHS hypotension can be achieved. In addition, the maternal discomfort of puerperas will not be caused by too high pressure.

\section{Acknowledgements}

This work was supported by the Scientific Research Project of Chengdu Municipal Health and Family Planning Commission (2015064). TX designed the experiment. TX and WL analyzed and interpreted the data. MY and XW recorded the basic information of puerperas. TX and WL wrote the manuscript. KZ and JW conceived the study and revised the manuscript. All authors read and approved the final manuscript.

\section{Conflict of interest}

None. 


\section{REFERENCES}

1. Laudenbach V, Mercier FJ, Rozé JC, et al. Epipage Study Group. Anaesthesia mode for caesarean section and mortality in very preterm infants: an epidemiologic study in the EPIPAGE cohort. Int J Obstet Anesth. 2009; 18(2): 142-149, doi: 10.1016/j.ijoa.2008.11.005, indexed in Pubmed: 19195873.

2. Klöhr S, Roth R, Hofmann T, et al. Definitions of hypotension after spinal anaesthesia for caesarean section: literature search and application to parturients. Acta Anaesthesiol Scand. 2010; 54(8): 909-921, doi: 10.1111/j.1399-6576.2010.02239.x, indexed in Pubmed: 20455872.

3. Stamer UM, Wulf H. Complications of obstetric anaesthesia. Curr Opin Anaesthesiol. 2001; 14(3):317-322, doi: 10.1097/00001503-20010600000006, indexed in Pubmed: 17019109.

4. Maronge L, Bogod D. Complications in obstetric anaesthesia. Anaesthesia. 2018; 73 Suppl 1: 61-66, doi: 10.1111/anae.14141, indexed in Pubmed: 29313912.

5. Saravanan S, Kocarev M, Wilson RC, et al. Equivalent dose of ephedrine and phenylephrine in the prevention of post-spinal hypotension in Caesarean section. Br J Anaesth. 2006; 96(1): 95-99, doi: 10.1093/bja/aei265, indexed in Pubmed: 16311286.

6. King HK, Wood L, Steffens $Z$, et al. Spinal anesthesia for cesarean section: isobaric versus hyperbaric solution. Acta Anaesthesiol Sin. 1999; 37(2): 61-64, indexed in Pubmed: 10410404.

7. Friedberg V, Martin K, Gerteis R. [Changes of vein pressure and renal function by different positions of pregnant women. (A contribution to the supine hypotensive syndrome) (author's transl)]. Geburtshilfe Frauenheilkd. 1974; 34(10): 809-817, indexed in Pubmed: 4442681.

8. Lemtis H, Seger R. [Supine hypotensive syndrome and obstetric anaesthesia (author's transl)]. Geburtshilfe Frauenheilkd. 1974; 34(9): 788-790, indexed in Pubmed: 4437570.

9. Morgan PJ, Halpern SH, Tarshis J. The effects of an increase of central blood volume before spinal anesthesia for cesarean delivery: a qualitative systematic review. Anesth Analg. 2001; 92(4): 997-1005, doi: 10.1097/00000539-200104000-00036, indexed in Pubmed: 11273939.
10. Dahlgren $\mathrm{G}$, Granath $\mathrm{F}$, Wessel $\mathrm{H}$, et al. Prediction of hypotension during spinal anesthesia for Cesarean section and its relation to the effect of crystalloid or colloid preload. Int J Obstet Anesth. 2007; 16(2): 128-134, doi: 10.1016/j.ijoa.2006.10.006, indexed in Pubmed: 17276668.

11. Riley ET. Editorial I: Spinal anaesthesia for Caesarean delivery: keep the pressure up and don't spare the vasoconstrictors. Br J Anaesth. 2004 92(4): 459-461, doi: 10.1093/bja/aeh084, indexed in Pubmed: 15013956.

12. Cooper DW, Carpenter M, Mowbray P, et al. Fetal and maternal effects of phenylephrine and ephedrine during spinal anesthesia for cesarean delivery. Anesthesiology. 2002; 97(6): 1582-1590, doi: 10.1097/00000542200212000-00034, indexed in Pubmed: 12459688.

13. Lee A, Ngan Kee WD, Gin T. A dose-response meta-analysis of prophylactic intravenous ephedrine for the prevention of hypotension during spinal anesthesia for elective cesarean delivery. Anesth Analg. 2004; 98(2): 483-90, table of contents, doi: 10.1213/01.ane.0000096183.49619. $\mathrm{fc}$, indexed in Pubmed: 14742392.

14. Erkinaro T, Mäkikallio K, Acharya G, et al. Divergent effects of ephedrine and phenylephrine on cardiovascular hemodynamics of near-term fetal sheep exposed to hypoxemia and maternal hypotension. Acta Anaesthesiol Scand. 2007; 51(7): 922-928, doi: 10.1111/j.1399-6576.2007.01 327.x, indexed in Pubmed: 17488314.

15. Berlac PA, Rasmussen YH. Per-operative cerebral near-infrared spectroscopy (NIRS) predicts maternal hypotension during elective caesarean delivery in spinal anaesthesia. Int J Obstet Anesth. 2005; 14(1): 26-31, doi: 10.1016/j.ijoa.2004.06.003, indexed in Pubmed: 15627535.

16. Zhou ZQ, Shao Q, Zeng Q, et al. Lumbar wedge versus pelvic wedge in preventing hypotension following combined spinal epidural anaesthesia for caesarean delivery. Anaesth Intensive Care. 2008; 36(6): 835-839, doi: 10.1177/0310057X0803600613, indexed in Pubmed: 19115653.

17. Kundra P, Khanna S, Habeebullah S, et al. Manual displacement of the uterus during Caesarean section. Anaesthesia. 2007; 62(5): 460-465, doi: 10.1111/j.1365-2044.2007.05025.x, indexed in Pubmed: 17448057.

18. Xiao TK, Li W, Zhang K, et al. Clinical of air pressure uterus bracket in preventing supine hypotensive syndrome during $\mathrm{C}$-section under combined spinal-epidural anesthesia. International Journal of Clinical and Experimental Medicine. 2017; 10(9): 13598-13606. 